\title{
Spontaneous natural formation of interspecific hybrids within the Festuca-Lolium complex
}

\author{
B. BOLLER ${ }^{1}$, J. HARPER ${ }^{2}$, E. WILLNER ${ }^{3}$, J. FUCHS ${ }^{4}$, M. GLOMBIK ${ }^{5,6}$, J. MAJKA $^{5,7}$, \\ V. MAHELKA ${ }^{8}$, C. ZHAO ${ }^{9}$, and D. KOPECKÝ ${ }^{5 *}$ \\ Langwiesstrasse 14, CH-8050 Zürich, Switzerland \\ Institute of Biological, Environmental and Rural Science, Aberystwyth University, SY233EE Aberystwyth, UK ${ }^{2}$ \\ IPK-Genbank Teilsammlungen Nord, D-23999 Malchow/Poel, Germany ${ }^{3}$ \\ Leibniz Institute of Plant Genetics and Crop Plant Research, D-06466 Gatersleben, Germany ${ }^{4}$ \\ Institute of Experimental Botany, Czech Acad Sci., Centre of the Region Haná for Biotechnological \\ and Agricultural Research, CZ-78371 Olomouc, Czech Republic ${ }^{5}$ \\ National Centre for Biomolecular Research, Faculty of Science, Masaryk University, \\ CZ-61137 Brno, Czech Republic ${ }^{6}$ \\ Institute of Plant Genetics, Polish Academy of Sciences, PL-60479 Poznan, Poland \\ Institute of Botany, Czech Acad. Sci., CZ-25243 Prìhonice, Czech Republic ${ }^{8}$ \\ Department of Environmental Systems Science, ETH Zürich, CH-8092 Zürich, Switzerland ${ }^{9}$
}

\begin{abstract}
Interspecific and intergeneric hybridization within the Festuca-Lolium complex is frequently used in forage plant breeding. However, little is known about the natural occurrence and competitiveness of such hybrids. We collected naturally formed hybrids between Festuca apennina, Festuca pratensis, and Lolium perenne in different habitats of Switzerland and the British Isles and studied their origin, the ease of their spontaneous formation, and their competitiveness with parental species. A special attention was paid to the largely sterile triploid forms and their rare sexual progeny. The triploid hybrid $F$. apennina $\times F$. pratensis proved to be widespread and often highly competitive in Swiss permanent pastures. The majority of these hybrids originated from $F$. apennina as the seed parent although little or no $F$. apennina grew nearby. In an experimental setting with ample $F$. pratensis pollen provided by neighbouring plants, up to $20 \%$ of seeds from open pollinated $F$. apennina plants were interspecific hybrids; among seeds collected in natural habitats, only $0.35 \%$ were hybrids. At an experimental site at $1000 \mathrm{~m}$ altitude, these triploid hybrids grew much more vigorously than corresponding tetraploid pure $F$. apennina, confirming their great competitiveness at such altitudes in permanent grasslands. The triploid hybrids were only marginally fertile suggesting that vegetative propagation by rhizomes is the cause of their competitive success in grassland. Moreover, triploid progeny retained the chromosome constitution of their mother plants indicating the possibility of apomixis. Natural triploid F. pratensis $\times$ L. perenne hybrids were partially female fertile (a seed set of $0.1 \%$ or less) whereas diploid hybrids did not produce any viable seeds. Progenies of these triploids showed considerable chromosome alterations, such as loss of a genome or recombination due to homoeologous pairing, and only rarely the chromosome constitution of the triploid mother plant was retained. It was concluded that natural triploid interspecific hybrids could expand the range of their progenitor species and might function as bridges transferring genes between them.
\end{abstract}

Additional key words: Festuca apennina, Festuca pratensis, Lolium perenne, triploid hybrid.

Submitted 15 May 2020, last revision 22 July 2020, accepted 27 July 2020. Festulolium special issue

Abbreviations: Fape - Festuca apennina; FCM - flow cytometry; Fp - Festuca pratensis; GISH - genomic in situ hybridization.

Acknowledgements: We would like to thank Prof. Adam J. Lukaszewski (University of California, Riverside) for his critical reading of the manuscript and valuable comments. The survey of occurrence of Festuca ploidy was funded as 06NAP-P51 by the programme NAP PGREL (Nationaler Aktionsplan zur Erhaltung und nachhaltigen Nutzung der pflanzengenetischen Ressourcen für Ernährung und Landwirtschaft) of the Swiss Federal Office for Agriculture. This research was partially funded by the Czech Science Foundation (grant award 20-10019S) and by the European Regional Development Fund OPVVV project "Plants as a tool for sustainable development" number CZ.02.1.01/0.0/0.0/16_019/0000827 supporting Excellent Research at CRH and the Czech Academy of Sciences Long-Term Research Development Project RVO 67985939. We thank Agroscope for letting us use their facilities.

* Corresponding author; e-mail: kopecky@ueb.cas.cz 


\section{Introduction}

Contrary to animals, plant species frequently engage in hybridization with representatives of different species, or even genera. Rieseberg (1997) reported that about $11 \%$ of plant species arose from interspecific hybridization, ranging from $22 \%$ for British flora to $5.8 \%$ for the mountain flora of North America. This would account for 27500 hybrids among the 250000 described plant species. Interspecific hybridization is often accompanied by whole genome duplication in the process called allopolyploidization, one of the key mechanisms of plant speciation. Allopolyploids represent a source of genetic, biochemical, and evolutionary novelty (Soltis and Soltis 1993). Wide hybridization may produce considerable heterosis, providing competitive advantage for the hybrids over their diploid progenitors (Comai 2005), masking deleterious recessive alleles leading to increased mutational robustness (Madlung 2013), and conveying increased stress tolerance through such mechanisms as delayed reproduction, fostering slower development, longer life span, and increased defense against herbivores and pathogens (Lohaus and Van de Peer 2016). In general, allopolyploids display broader adaptation to novel environmental niches compared to their progenitor species, allowing them to expand their range beyond those of the parental species (Te Beest et al. 2012). A wellknown example within the Festuca-Lolium complex is the hexaploid grass species tall fescue (Festuca arundinacea Schreb.), which originated by a hybridization event involving winter hardy $F$. pratensis Huds. with droughtresistant F. glaucescens Boiss. (Humphreys et al. 1995) and was subsequently capable of colonizing climatically diverse European grasslands.

Besides the key role that allopolyploidy plays in plant evolution and diversification, these processes are key to the origin of many crops including wheat, banana, rapeseed, and cotton (Wendel 2015 and references therein). Interspecific hybridization is also frequently used in plant breeding. Targeted merging of two genomes into a single organism offers an opportunity to combine agriculturally important characteristics of two species, to introgress one or a few traits from a contrasting cultivated or a wild relative into elite cultivars of crops, or to widen the gene pools of a crop. It seems that some plant families are more prone to interspecific hybridization and allopolyploidization than others. It has been shown that Poaceae species are among those with a high proportion of allopolyploids (Ellstrand 1996). Interspecific hybridization was used to introgress agriculturally beneficial traits from wild or cultivated relatives to wheat, one of the three key crops for human's food consumption (Matsuoka 2011).

The Festuca-Lolium complex is represented by ryegrasses (Lolium spp.) and broad-leaved fescues (Festuca spp.) from subgenus Schedonorus. Close phylogenetic relationship of the species enables numerous hybridization combinations within the complex, giving rise to hybrids found in nature (Banfi et al. 2017). The most frequent among such natural hybrids known so far are $L$. perenne $\times F$. pratensis found in the British Isles and Northwestern Europe (Farragher 1975, Lewis 1975). These hybrids occur in mature meadows and are often found on waterlogged soils (Humphreys and Harper 2008). As they occur in soils prone to episodic flooding in lowland areas in old grassland and water meadows throughout the UK (Stace 1975), they are thought to offer breeding opportunities for adaptation to waterlogged soils. This may become an important plant breeder's objective, given increased occurrences of localized or widespread flooding exacerbated by climate change (Humphreys and Harper 2008).

In 2015, we conducted an expedition in the Swiss Alps to collect specimens of $F$. apennina De Not. This allotetraploid arose from hybridization of $F$. pratensis with a so-far unidentified fescue species and thus, it is closely related to $F$. pratensis (Kopecký et al. 2016). Due to the morphological similarity between $F$. apennina and F. pratensis, some authors (e.g. Conert and Hegi 1998) describe $F$. apennina as a subspecies of $F$. pratensis. However, cytological evidence conclusively shows it as a distinct allopolyploid species (Kopecký et al. 2016) and it should be referred to as $F$. apennina De Not., paying tribute to the original description by De Notaris (1844). Surprisingly, in our 2015 collection, we found many triploid plants along with tetraploid $F$. apennina and diploid $F$. pratensis (it is difficult to distinguish all three cytotypes from each other in their vegetative stage). Our cytogenetic and molecular analysis revealed that triploids are hybrids of the two, and originated from reciprocal crosses between F. apennina and $F$. pratensis where both could be the maternal species, though $F$. apennina is the maternal parent more frequently. The presence of these three cytotypes is altitude dependent, with tetraploid $F$. apennina growing over $1200 \mathrm{~m}$ a.s.l. and diploid F. pratensis below $1800 \mathrm{~m}$ a.s.l. Triploid hybrids occur in the overlapping zone, often in sympatry with at least one, or both parents. However, in some locations, triploids were the only cytotype identified indicating their high competitiveness (Kopecký et al. 2018). Besides these two, other hybrids were sporadically found in nature with various taxonomical treatment (Holub 1998, Banfi et al. 2017).

It is believed that naturally formed hybrids of the Festuca-Lolium complex are generally sterile (at least male sterile) and thus, will not lead to the establishment of a new (hybrid) species (Jauhar 1993). However, they may persist by vegetative reproduction. We observed that triploid hybrids of $F$. apennina $\times F$. pratensis readily propagate vegetatively via rhizomes, which may distribute an individual over long distances. Our analysis revealed clones of an individual dispersed up to $14.4 \mathrm{~m}$ in Swiss swards (Kopecký et al. 2018). Another means of transmission of the hybrid genome into subsequent generations might be via backcrosses of a partially femalefertile hybrid to one of the parental species. Natural hybrids of $L$. perenne $\times F$. pratensis in British Isles and France were found to be diploids and triploids formed by fusion of reduced and unreduced gametes (with both combinations LLF and LFF) (Peto 1933, Wit 1964, Essad 1966, Gymer and Whittington 1973, Humphreys and Harper 2008). Although fertility of the hybrids was low, normal viable 
pollen grains were occasionally recovered from both diploid and triploid hybrids (Humphreys and Harper 2008). This indicates that gene flow is likely between natural populations of the hybrids and their progenitors.

This paper aimed to provide an update on interspecific and intergeneric hybridization within the FestucaLolium complex. Special attention was paid to the origin of hybrids, their establishment in natural stands, and competitiveness over the parental species.

\section{Materials and methods}

Survey of altitudinal distribution of broad-leaved Festuca species: The altitudinal distributions of diploid $F$. pratensis, tetraploid $F$. apennina, and their triploid hybrids were studied by sampling plants in six natural grassland areas representing four different Swiss cantons (Table 1 Suppl.). A majority of the sampling sites were used as pasture for cattle grazing. However, at low altitudes, some grasslands were used for hay or silage making and had to be included where no grazed areas were available. At highest altitudes, some scrubby zones with little grazing were included. For each of the grassland areas, one or two contiguous pastures of at least $2000 \mathrm{~m}^{2}$ at mid-altitude (1 350 to $1550 \mathrm{~m}$ a.s.1.) were chosen. A $20 \times 20 \mathrm{~m}$ grid was pre-defined by a geographic information system (GIS) in each pasture. Starting with a random square of $20 \times 20 \mathrm{~m}$ within this grid, the broad-leaved Festuca plant closest to the centre of the square was sampled. This was continued with adjacent squares until at least 50 plants were sampled. Squares with no Festuca present were skipped. Starting from the $2000 \mathrm{~m}^{2}$ pastures, an altitudinal gradient up and down the slope was followed. Additional sampling was carried out in horizontal transects every $50 \mathrm{~m}$ of altitude. Six plants were sampled at each altitude $(+/-10 \mathrm{~m})$ with a distance of about $15 \mathrm{~m}$ (20 steps) between the plants. For each of the six grassland areas, a total of 18 to 21 such horizontal transects, covering altitudes of 850 to $1950 \mathrm{~m}$ a.s.l. were included (Fig. 1 Suppl.). The highest and the lowest horizontal transects at each locality were from 2.7 to $4.9 \mathrm{~km}$ far from each other. From each plant, a ramet was detached and planted into a Quickpot tray. Ramets were then allowed to develop in a greenhouse.

Ploidy was determined by flow cytometry (FCM) in two laboratories, Olomouc, Czech Republic and Gatersleben, Germany. At Olomouc, each ramet was measured separately as described by Doležel et al. (2007). Nuclear suspensions were prepared from $50 \mathrm{mg}$ leaf tissues of each sample with Pisum sativum cv. Ctirad used as the reference standard having 2C $=9.09 \mathrm{pg}$ (Doležel et al. 1998). At Gatersleben, nuclear suspensions were prepared from equal amounts of $50 \mathrm{mg}$ leaf tissues of each of one to three ramets together with Vicia faba, cv. Tinova (IPK gene bank accession number: FAB 602) as internal reference standard using the CyStain PI Absolute $P$ reagent kit (Sysmex, Norderstedt, Germany) according to manufacturer's instructions. When ploidy deviations were observed within the pools of up to three ramets, each ramet was measured individually, together with $V$. faba.
Diploid plants were considered as $F$. pratensis, tetraploid plants as $F$. apennina, and triploid plants as hybrids of the two. In each locality, 12 triploid plants were selected for determination of maternity. They were selected to best cover the altitudinal range of triploid plant occurrence at each locality. Maternity was determined by analysis of two cpDNA loci. Firstly, a 5-bp indel in the trnL-trnF intergenic spacer differentiated between $F$. pratensis and F. apennina haplotypes (Kopecký et al. 2018), but it does not differentiate between $F$. pratensis and $L$. perenne (another potential mating partner) haplotypes. Therefore, a second marker, the gene coding for maturase $\mathrm{K}$ ( mat $K$ ), was used to differentiate between $F$. pratensis and L. perenne haplotypes. Analysis of Genbank records showed that the matK region contained three differentiating positions (based on accession HM453060): 514 (C/A), 612 (T/A), and $884(\mathrm{~T} / \mathrm{C})$. The analysis of $\operatorname{trn} \mathrm{L}-\operatorname{trn} \mathrm{F}$ intergenic spacer was done as described in our previous report (Kopecký et al. 2018). matK region was amplified using primers F318poales and R1460poales (De Vere et al. 2012) as follows: reaction volumes of $25 \mathrm{~mm}^{3}$ contained $12.5 \mathrm{~mm}^{3}$ of Combi PPP MasterMix (TopBio, Vestec, Czech Republic), $9.5 \mathrm{~mm}^{3}$ of $\mathrm{ddH}_{2} \mathrm{O}, 0.5 \mu \mathrm{M}$ of each primer, and 5 - 10 ng of genomic DNA. The thermocycling profile was as follows: $95{ }^{\circ} \mathrm{C} / 5 \mathrm{~min}, 35 \times\left(95{ }^{\circ} \mathrm{C} / 30 \mathrm{~s}, 53{ }^{\circ} \mathrm{C} / 30 \mathrm{~s}\right.$, $\left.72^{\circ} \mathrm{C} / 1 \mathrm{~min}\right), 72^{\circ} \mathrm{C} / 10 \mathrm{~min}$. PCR products were purified using the QIAquick PCR purification kit (Qiagen, Hilden, Germany) and sequenced (GATC Biotech, Cologne, Germany) using the PCR primers.

Formation of triploid $F$. apennina $\times F$. pratensis hybrids under controlled open pollination: For the assessment of the formation of triploid hybrids under controlled pollination, we used $F$. apennina (Fape) and $F$. pratensis $(F p)$ plants as well as their triploid hybrids which ploidy was confirmed by FCM as described above. The plants originated from a small collection in different European countries carried out in 2017 and were cultivated in an experimental field of Agroscope in Reckenholz. Broadleaved Festuca was collected in Austria (Arlberg region), Bulgaria (Rila mountains), Italy (Cortina d'Ampezzo region), Liechtenstein (Alp Malbun region), Romania (Transylvanian Alps), and Switzerland (Glaubenbielen and Steiner Berg regions, see Table 1 Suppl.). All plants were collected from permanent grassland at altitudes between 1310 and $2000 \mathrm{~m}$ a.s.l. They were planted at random at $0.5 \times 0.25 \mathrm{~m}$ distances in an $11 \times 2.5 \mathrm{~m}$ field plot at Zürich-Reckenholz in August 2017. Plants were trimmed to $5 \mathrm{~cm}$ stubble height in autumn 2017. During the spring growth in 2018, inflorescence emergence was observed visually at 3- to 4-d intervals and the date of the inflorescence emergence interpolated. Flowering synchrony between a pair of plants was estimated based on the date of inflorescence emergence, assuming an equal delay between inflorescence emergence and flowering. After completion of inflorescence emergence, 29 Fape, 34 $F p$, and 25 triploid hybrid plants were selected so that each country of origin was represented by at least two genotypes of Fape. Selected plants were allowed to flower and crosspollinate openly; all remaining plants were trimmed to 5 
cm stubble height. No feral Festuca plants flowered closer than $200 \mathrm{~m}$ from the selected plants. Seeds were harvested individually from each plant at the start of shedding. Further investigation was initiated with the seeds obtained from Fape and triploid hybrid plants. About 200 seeds for each of the Fape mother plant were germinated at room temperature. However, the germination rate was low $(2.7 \%)$. Therefore, remaining seeds were subjected to consecutive cycles of cold treatment $\left(4{ }^{\circ} \mathrm{C}\right.$ for $\left.14 \mathrm{~d}\right)$ followed by two weeks at room temperature. Up to three cycles were applied to increase the germination rate which reached $73.7 \%$, on average. All seeds collected from triploid hybrids ( 0 to 5 seeds per plant, 1.5 on average) were subjected to cold treatment $\left(4^{\circ} \mathrm{C}\right.$ for $\left.21 \mathrm{~d}\right)$ and then allowed to germinate at room temperature. Ploidy of seedlings was determined by FCM as described above. We analyzed all seedlings from Fape mother plants germinating without cold treatment and a sample of seedlings germinating with one, two, or three cycles of cold treatments. All seedlings obtained from triploid mothers, 8 in total, were analyzed.

Formation of triploid hybrid progeny in situ and their performance: Seeds were collected individually from a total of $49 \mathrm{~F}$. apennina plants at 11 natural grassland localities in Switzerland in 2017, at the altitudes of 1525 to $1850 \mathrm{~m}$ a.s.l. Five localities were in the grassland areas of Glaubenbielen (two localities), Kamor, Steiner Berg and Selamatt (see Table 1). Six further localities were in the municipalities of Trimmis and Sedrun (ct. Graubünden), Boltigen and Guttannen (ct. Bern), Bedretto (ct. Ticino) and Ulrichen (ct. Wallis). The ploidy of each plant (and thus, their assignment to Fape) was determined from single leaves by FCM. Ploidy of at least 35 individuals randomly sampled in the surrounding area of the plants was determined by FCM using the pooling approach of up to three ramets, as described above. At all sites except Guttannen and Sedrun, triploid hybrids were observed in the neighborhood of the Fape plants from which the seeds were collected. Depending on availability, up to 50 seeds per plant were subjected to two cycles of cold treatment $\left(4^{\circ} \mathrm{C}\right.$ for $\left.14 \mathrm{~d}\right)$ and seedlings were planted to Quickpot boxes in the greenhouse. At least three seedlings were obtained from each of 46 Fape mother plants (out of 49 plants; three plants did not produce any seeds). In total, 860 seedlings reached the stage (at least two leaves) for ploidy determination. Ploidy of all seedlings was determined by FCM as described above. Plants with ploidy other than tetraploid were studied for chromosome constitution by genomic in situ hybridization (GISH). Mitotic metaphase spreads prepared from root tips and GISH were performed according to Masoudi-Nejad et al. (2002). The allotetraploid $F$. apennina consists of two genomes, one of $F$. pratensis $(F p)$ and the other one close to current $F$. glaucescens ( $F g$-like; Kopecký et al. 2016). In order to determine genome composition, total genomic DNAs of F. pratensis and F. glaucescens were used as probes labelled with digoxigenin and tetramethylrhodamine-5-dUTP, respectively, using Nick Translation kits according to manufacturer's recommendation (Roche Applied Science, Penzberg, Germany). Total genomic DNA of L. multiflorum was sheared to 200 - $500 \mathrm{bp}$ fragments by boiling for $45 \mathrm{~min}$ and used as blocking DNA. The probe to block ratio was 1:150 with minor variation. The digoxigenin labelled probe was detected by the Anti-DIG-FITC (Roche Applied Science). Chromosomes were counterstained with $1.5 \mu \mathrm{g} / \mathrm{ml}$ 4',6-diamidino-2-phenylindole (DAPI) in Vectashield antifade solution (Vector Laboratories, Burlingame, CA, USA). Slides were evaluated with an Olympus $A X 70$ epifluorescent microscope equipped with a SensiCam $B / W$ camera (Olympus, Tokyo, Japan). ScionImage, and Adobe Photoshop software were used for processing and pseudo-colouring of the images.

Field performance of triploid, tetraploid, and hexaploid progeny obtained from in situ pollination was tested at two sites, Reckenholz (440 m a.s.1.) and Früehbüehl (1 $000 \mathrm{~m}$ a.s.1.). Each of three $3 x$ and four $6 x$ genotypes were compared to five $4 x$ genotypes to which they were half-sibs. Since each of the $3 x$ and $6 x$ genotypes was from a different Fape mother, $5 \times(3+4)=35$ tetraploid genotypes were used. Ten genotypes of the autotetraploid $F$. pratensis cv. Tetrax were used as a control. The 52 (three triploids, four hexaploids, 35 tetraploids, and 10 autotetraploid $F p$ ) genotypes were clonally propagated to 6 ramets each. Field experiments were in spring 2018 in a completely randomized block design $(0.5 \times 0.3 \mathrm{~m})$. At each site, three replications (blocks) were used with separate randomization of the 52 genotypes in each block. Performance of the genotypes was estimated by vigor scores on a 9 (very vigorous) to 1 (plant dead) scale. Vigor was scored three times at Reckenholz and twice at Früehbüehl in the planting year A0 (2018), and five times at Reckenholz and four times at Früehbüehl in the first full harvest year H1 (2019).

Fertility and gene flow in natural $L$. perenne $\times$ F. pratensis hybrids: Natural hybrids were collected from waterlogged soils in the Thames valley near Oxford based on their inflorescence morphology (Humphreys and Harper 2008). The plants were checked for ploidy using Cyflow space flow cytometer (see above). Three plants were found to be mixoploids with diploid and triploid tillers; these plants were divided into individual tillers and each tiller was analyzed using flow cytometer before the plants were put into isolation units. Chromosome counts and GISH (see above) were used to confirm the chromosome numbers and reveal the genomic constitution of the plants. The natural hybrids were subsequently classified into three groups: diploid FpLp, triploids FpFpLp and LpLpFp.

Pollen fertility of the hybrids and their progeny was estimated by acetocarmine staining (Shreiber 1954). To investigate the possibility of production of new hybrids and the potential gene flow between species, controlled pollination experiments in pollen-proof isolation units were initiated. The isolation units had positive displacement of air through filters to ensure no rogue pollen could enter the unit. The natural hybrids were cloned, and two clonal ramets of each hybrid genotype were put into each isolation unit with different combinations of diploid and tetraploid $L$. perenne and $F$. pratensis (each genus represented by at least 10 different genotypes). In isolation units 5 and 6 , a 
single genotype of L. perenne or F. pratensis was separated into 10 clonal ramets.

Six different isolation units involved these genotypes: 1) natural hybrids $(2 x$ and $3 x$ ) and $F$. pratensis and $L$. perenne (both species $2 x$ and $4 x$ )

2) natural hybrids only ( $2 x$ and $3 x$ )

3 ) natural hybrids ( $2 x$ and $3 x$ ) and L. perenne $(2 x)$

4) natural hybrids $(2 x$ and $3 x)$ and $F$. pratensis $(2 x)$

5 ) natural hybrids $(2 x$ and $3 x)$ and a single genotype of diploid L. perenne

6) natural hybrids ( $2 x$ and $3 x$ ) and a single genotype of diploid $F$. pratensis.

After flowering, the plants were removed from the isolation units and the number of florets and seed were counted for an estimate of seed yield and hence fertility of the natural hybrids in different isolation combinations. A sample of the progeny produced from these isolation units was established and analyzed for chromosome number, genomic constitution using GISH and fertility.

\section{Results}

A general altitudinal pattern of the distribution of diploid Festuca pratensis (2x Fp), Festuca apennina (4x Fape), and their triploid $(3 x)$ hybrids was found in all six sampled grassland areas in the Swiss Alps (Fig. 1). Diploid Fp was the sole species at the lowest altitudes, and tetraploid Fape was the sole species at the highest altitudes, except for the grassland area Reichenbachtal. Triploid hybrids prevailed at mid-altitudes at variable frequencies but were often the most abundant and sometimes even the sole cytotype. However, the six grassland areas differed in the altitudinal levels at which dominance of a cytotype changed. For example, $3 x$ hybrids were strictly restricted to a zone between 1150 and $1350 \mathrm{~m}$ a.s.l. in the grassland area Oberseetal. Conversely, triploids were found between 1000 and 1950 m a.s.l. in Reichenbachtal. Fp and Fape did not co-occur in balanced abundance frequently. In just one out of 8 pastures of over $2000 \mathrm{~m}^{2}$ each with at least 47 specimens, at locality Passhöhe in grassland area Glaubenbielen, the less frequent species of $2 x F p$ and $4 x$ Fape occurred with more than $4 \%$ (Table 1). Triploid hybrids and just one of the parents were present in three $2000 \mathrm{~m}^{2}$ pastures, and only triploid hybrids were present in one pasture. In the remaining three pastures, both $F p$ and Fape were present, but the less frequent of the two was present with only 2 to $3.5 \%$. Similarly, among the 108 additional horizontal transects shown in Fig. 1 with six plants sampled, at only 5 transects both $F p$ and Fape were found. At 42 transects $3 x$ hybrids and only one of the parent species were found, and at 10 transects all samples were $3 x$ hybrids. At the remaining 51 transects, either $F p$ or Fape were the sole species found.

A great majority $(82 \%)$ of randomly selected 72 triploid hybrids among the plants represented in Fig. 1 was derived from Fape as the seed parent (Table 2). Just $17 \%$ of triploids were derived from a $F p$ mother. One of the 72 plants $(1 \%)$ was derived from a Lolium parent and was identified by GISH to be a Festulolium hybrid
Lolium perenne $\times F$. apennina. The analysis of cpDNA revealed Lolium as the maternal parent of this hybrid. The altitudinal distribution of maternity of the hybrids was not related to the relative frequency of the parental species at respective altitudes (Table 2). One might expect that at lower altitudes, relatively more hybrids would be derived from $F p$ mother, and less so at higher altitudes where $F p$ are less frequent compared to Fape. However, even at altitudes below $1225 \mathrm{~m}$ a.s.l. where no Fape plants were found in any of the grassland areas investigated, over $80 \%$ of triploid hybrids were derived from a Fape mother.

At least some seeds were obtained from 27 out of 29 Fape plants, with each of the seven countries of origin (Austria, Bulgaria, Italy, Romania, Liechtenstein, and Switzerland) represented, when exposed to open pollination of the set of 29 plants of Fape, 34 plants of $F p$, and 25 plants of triploid hybrid in an isolated experimental field plot of about $30 \mathrm{~m}^{2}$. However, triploid hybrids did not shed any pollen. Out of 116 seedlings which germinated without cold treatment $113(97 \%)$ were $3 x$ hybrids; the remaining three seedlings were tetraploid Fape. From the seedlings germinating after one, two, or three cycles of cold treatment, only 14,8 , and $4 \%$ were $3 x$ hybrids, respectively, and the rest were tetraploids. When tetraploid progeny of a given mother plant required several cycles of cold treatment for germination, about half of the triploid progeny of that plant also required cold for germination. Although a single cycle of cold treatment was sufficient for germination of the majority of the tetraploid progeny of a mother plant, a large majority of its triploid hybrid progeny germinated without cold treatment. Based on this observation, we calculated a linear regression of the percentage of triploid progeny germinating without cold treatment on the number of cold treatment cycles required for germination of the remaining, predominantly tetraploid, progeny of the same tetraploid mother plant. This regression was used to estimate the total number of triploid progeny for those mother plants where only the number of triploid progeny germinating without cold treatment and the cold requirement for germination of the remaining seeds was determined.

Formation of $3 x$ progeny was significantly $\left(r^{2}=0.55\right.$, $n=29$ ) correlated with relative chances of pollination by $F p$ plants based on the distance and flowering synchrony of neighboring Fape and Fp plants in the field (Fig. 2). The chances were calculated assuming a drop in the pollination chance within the square of the metric distance between two plants, and with a $10 \%$ drop per day of flowering asynchrony. According to the linear regression shown in Fig. 2, the receptivity of a $4 x$ Fape stigma was about six times less for pollen of $F p$ than for pollen of Fape. However, there were differences among regions of origin and plants within a region of origin. Both Fape plants from Italy, three out of four from Romania and two out of eight from Bulgaria were clearly less prone to form $3 x$ hybrids than those from other regions. Three Fape individuals, one each from Austria, Liechtenstein, and Switzerland, produced more than double the number of $3 x$ hybrid progeny than would be expected from the respective pollination probability by a neighboring $F p$ plant. 


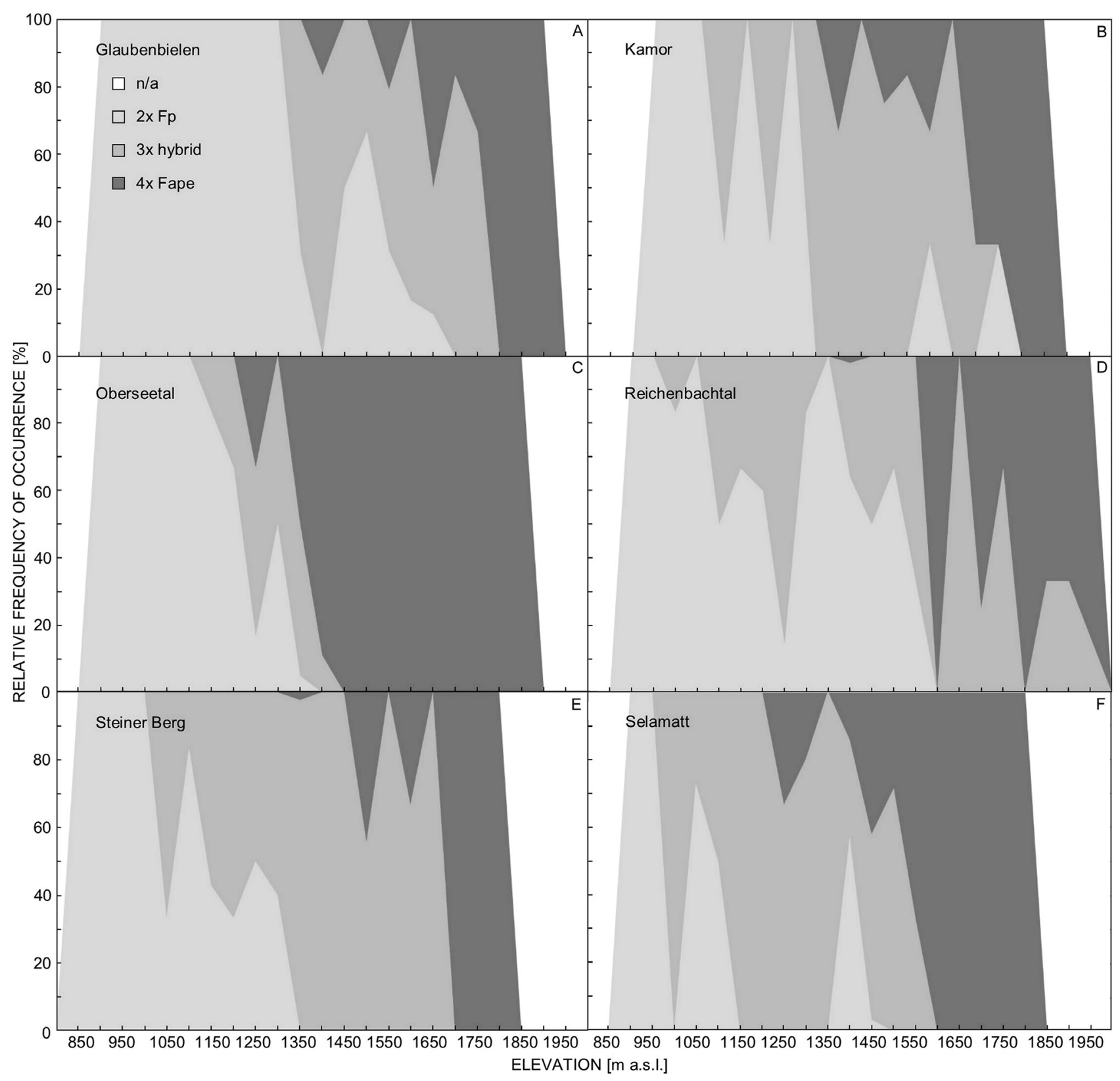

Fig. 1. The distribution of ploidy of broad-leaved Festuca individuals sampled in six permanent grassland areas at different altitudes scaled by $50 \mathrm{~m}$. $A$ - Glaubenbielen, $B$ - Kamor, $C$ - Oberseetal, $D$ - Reichenbachtal, $E$ - Steiner Berg, and $F$ - Selamatt. Light grey diploid Festuca pratensis, dark grey - tetraploid F. apennina, grey - triploid hybrids.

Out of 860 seedlings obtained from 49 Fape plants collected at 11 localities in Switzerland, just three seedlings $(0.35 \%)$ were triploid hybrids (Table 2 Suppl.). GISH confirmed that they originated from in situ pollination with a $F p$ pollen. Each of these three seedlings was from a different Fape mother plant, but two of them grew in the same locality, Schribersboden (grassland area Selamatt). The third one was collected in the locality Küeschte (grassland area Kamor). Both these grassland areas were also the object of an extensive survey of the occurrence of Fp, Fape, and their $3 x$ hybrids reported above (see Fig. 1 Suppl.). At Küeschte, several potential $F p$ pollen donors were found in the vicinity of the Fape plant, the closest one at a distance of $47 \mathrm{~m}$. However, no $F p$ was found among 51 individuals sampled in the pasture around the Fape mothers at Schribersboden. The nearest Fp plant in that survey was at a distance of about $1400 \mathrm{~m}$ from the Fape plants which were mothers of those two triploid seedlings. The rare occurrence of triploids among the progeny of Fape was in contrast with the abundance of triploid plants in these localities. The frequency of triploid seed emergence from Fape plants at the localities Schribersboden and Küeschte was $0.63 \%$ (two out of 317 seedlings) and $0.68 \%$ (one out of 147 seedlings), however, $49 \%$ (25 out of 51 plants), and $33 \%$ (19 out of 57) plants found in nearby pastures, respectively, were 
Table 1. The distribution of ploidy among at least 47 randomly sampled broad-leaved Festuca species in 8 pastures of at least $2000 \mathrm{~m}^{2}$ in the Swiss Alps with a different mean elevation. Fp - Festuca pratensis, Fape - Festuca apennina.

\begin{tabular}{llllrrr}
\hline Elevation [m a.s.1.] & Locality & Grassland area & $\begin{array}{l}\text { Number of } \\
\text { samples }\end{array}$ & $2 x F p$ & $3 x$ hybrids & $4 x$ Fape \\
\hline 1364 & Mörlialp & Glaubenbielen & 59 & 30.5 & 69.5 & 0.0 \\
1566 & Passhöhe & Glaubenbielen & 48 & 31.3 & 47.9 & 20.8 \\
1406 & Loch & Kamor & 48 & 0.0 & 100.0 & 0.0 \\
1372 & Saaftenboden & Oberseetal & 47 & 2.1 & 25.5 & 72.3 \\
1398 & Chaltenbrunnen & Reichenbachtal & 50 & 64.0 & 34.0 & 2.0 \\
1385 & Ahorn & Steiner Berg & 70 & 0.0 & 98.6 & 1.4 \\
1445 & Zinggen & Selamatt & 57 & 3.5 & 54.4 & 42.1 \\
1526 & Schribersboden & Selamatt & 51 & 0.0 & 49.0 & 51.0 \\
\hline
\end{tabular}

Table 2. The maternity of $3 x$ hybrids sampled in six Swiss grassland areas at different altitudes compared to the relative occurrence of their parent species, Festuca pratensis and $F$. apennina $\left({ }^{1}\right.$ - plus one plant from a Lolium perenne mother; ${ }^{2}$ - two plants from less than $1025 \mathrm{~m}$ a.s.l., both from F. apennina mother). Fp - Festuca pratensis, Fape - Festuca apennina.

\begin{tabular}{lccccc}
\hline $\begin{array}{l}\text { Altitudinal range } \\
\text { [m a.s.1.] }\end{array}$ & $\begin{array}{l}\text { Distribution of ploidy of randomly sampled } \\
\text { Festuca plants } \\
2 x F p\end{array}$ & $3 x$ hybrids & $4 x$ Fape & $\begin{array}{l}\text { Maternity of selected 3x } \\
\text { hybrids }\end{array}$ & Fape [\%] \\
\hline$<1225$ & 76.1 & 23.9 & 0 & $2(18.2)$ & $9(81.8)^{2)}$ \\
1225 to 1325 & 45.7 & 47.1 & 7.1 & $3(33.3)$ & $6(66.7)$ \\
1325 to 1425 & 20.1 & 66.8 & 13.2 & $3(13.6)$ & $19(86.4)$ \\
1425 to 1525 & 11.9 & 54.5 & 33.6 & $3(27.3)^{1)}$ & $7(63.6)$ \\
1525 to 1625 & 13.8 & 42.8 & 43.4 & $1(7.7)$ & $12(92.3)$ \\
$>1625$ & 1.9 & 21.4 & 76.7 & $0(0.0)$ & $6(100.0)$ \\
\hline
\end{tabular}

triploids. This was only slightly higher than the frequency of triploids identified among 540 broad-leaved Festuca plants collected over all 11 localities $(26 \%)$.

However, not all of the remaining seedlings (out of 860) had the expected $4 x$ ploidy. Five of them were hexaploid. The GISH revealed that they resulted from fertilization involving one reduced and one unreduced gamete of Fape. All three triploid and four of the five hexaploid seedlings developed sufficiently to assess their vigor in a field experiment (see below).

We investigated the vigour of the three triploid and four hexaploid seedlings compared to their tetraploid halfsiblings and ten genotypes of tetraploid $F p$ cv. Tetrax. For each of the triploid and hexaploid seedlings, five randomly selected tetraploid half-siblings were chosen. All three triploid hybrid genotypes outperformed their tetraploid Fape half-siblings at both experimental locations, Früehbüehl (1000 m a.s.1) and Reckenholz (450 m a.s.1.) (Table 3). The difference increased from the planting year (A0) to the first full harvest year (H1). At Früehbüehl, $3 x$ hybrids were also significantly more vigorous than the tetraploid Fp cv. Tetrax. At Reckenholz, there was no significant difference between the performance of $3 x$ hybrids and Tetrax. Tetraploid Fape performed similarly to Tetrax at Früehbüehl but much poorer at Reckenholz. Hexaploid plants were always less vigorous compared to the tetraploid siblings. The difference was significant for all years and locations, except for Reckenholz in H1. Similar as $4 x$ Fape, $6 x$ Fape plants performed much better at Früehbüehl (1 $000 \mathrm{~m}$ a.s.1.) when compared to Reckenholz (450 m a.s.l).

Indehiscent anthers were observed in all $3 x$ hybrids at the flowering stage, indicating complete male sterility (Fig. 2 Suppl.). This characteristic allows visual identification of triploids in the field. However, a certain, though an extremely low female fertility was observed. Out of 25 triploid hybrids allowed to reach the seed ripening stage in a field at Reckenholz grown in the presence of 29 Fape and $34 \mathrm{Fp}$ plants, 15 plants produced a few (one to five) seeds, 28 in total. The germination rate of these seeds was only $25 \%$ (seven out of 28 ), compared to $74 \%$ of Fape and $90 \%$ of $F p$. Those seven germinating seeds originated from four $3 x$ mother plants (Table 3 Suppl.). Compared to Fape and $\mathrm{Fp}$ plants of similar vigour, this corresponds to 0.02 and $0.004 \%$ viable seed set of these cytotypes, respectively.

Of the 7 progenies of triploid hybrids, 4 were tetraploid and 3 were triploid. Tetraploids were less vigorous than triploids and only one tetraploid plant was still alive when GISH analysis was carried out. Chromosome constitution of this $4 x$ progeny plant was $21 F p+7 F g$-like chromosomes, suggesting a scenario of an unreduced egg cell of the 
Table 3. Annual averages of vigor scores (scale 1 to 9,9 is best) of three $3 x$ hybrid and four $6 x$ Festuca apennina genotypes compared to the average of 5 regular $4 x F$. apennina progeny of the corresponding $F$. apennina mother plant, or 10 genotypes of $4 x F$. pratensis cv. Tetrax. Means within a row not followed by the same letter are significantly different $(P<0.05)\left({ }^{1}\right.$ - comparisons $3 x$ vs. $4 x$ and $4 x$ vs. $6 x$ : the $F$-test for the factor "ploidy" in an analysis of variance with a model of y = ploidy mother replication; ${ }^{2}-$ comparisons with $4 x$ F. pratensis Tetrax: Duncan's multiple range test, model y = ploidy replication). Fp - Festuca pratensis, Fape - Festuca apennina .

\begin{tabular}{|c|c|c|c|c|c|c|}
\hline Trial site (altitude) & Year & Comparison & $3 x$ hybrid $^{1}$ & $4 x$ Fape $^{1}$ & $6 x$ Fape $^{1}$ & $4 x F p$ Tetrax $^{2}$ \\
\hline \multirow[t]{4}{*}{ Früehbüehl (1000 m a.s.l.) } & \multirow[t]{2}{*}{ A0 } & $3 x$ vs. $4 x$ & \multirow[t]{2}{*}{$8.83^{\mathrm{a}}$} & $7.26^{\mathrm{b}}$ & & \multirow[t]{2}{*}{$6.76^{\mathrm{b}}$} \\
\hline & & $4 x$ vs. $6 x$ & & $6.67^{b}$ & $5.63^{\mathrm{c}}$ & \\
\hline & \multirow[t]{2}{*}{$\mathrm{H} 1$} & $3 x$ vs. $4 x$ & \multirow[t]{2}{*}{$8.94^{\mathrm{a}}$} & $6.45^{\mathrm{b}}$ & & \multirow[t]{2}{*}{$6.59^{\mathrm{b}}$} \\
\hline & & $4 x$ vs. $6 x$ & & $6.20^{\mathrm{b}}$ & $4.69^{c}$ & \\
\hline \multirow[t]{4}{*}{ Reckenholz (450 m a.s.1.) } & \multirow[t]{2}{*}{ A0 } & $3 x$ vs. $4 x$ & \multirow[t]{2}{*}{$7.85^{\mathrm{a}}$} & $3.51^{\mathrm{b}}$ & & \multirow[t]{2}{*}{$6.99^{\mathrm{a}}$} \\
\hline & & $4 x$ vs. $6 x$ & & $3.22^{\mathrm{b}}$ & $2.27^{\mathrm{c}}$ & \\
\hline & \multirow[t]{2}{*}{ H1 } & $3 x v s .4 x$ & \multirow[t]{2}{*}{$6.49^{\mathrm{a}}$} & $1.93^{\mathrm{b}}$ & & \multirow[t]{2}{*}{$7.29^{\mathrm{a}}$} \\
\hline & & $4 x v s .6 x$ & & $1.37^{\mathrm{b}}$ & $1.00^{\mathrm{b}}$ & \\
\hline
\end{tabular}

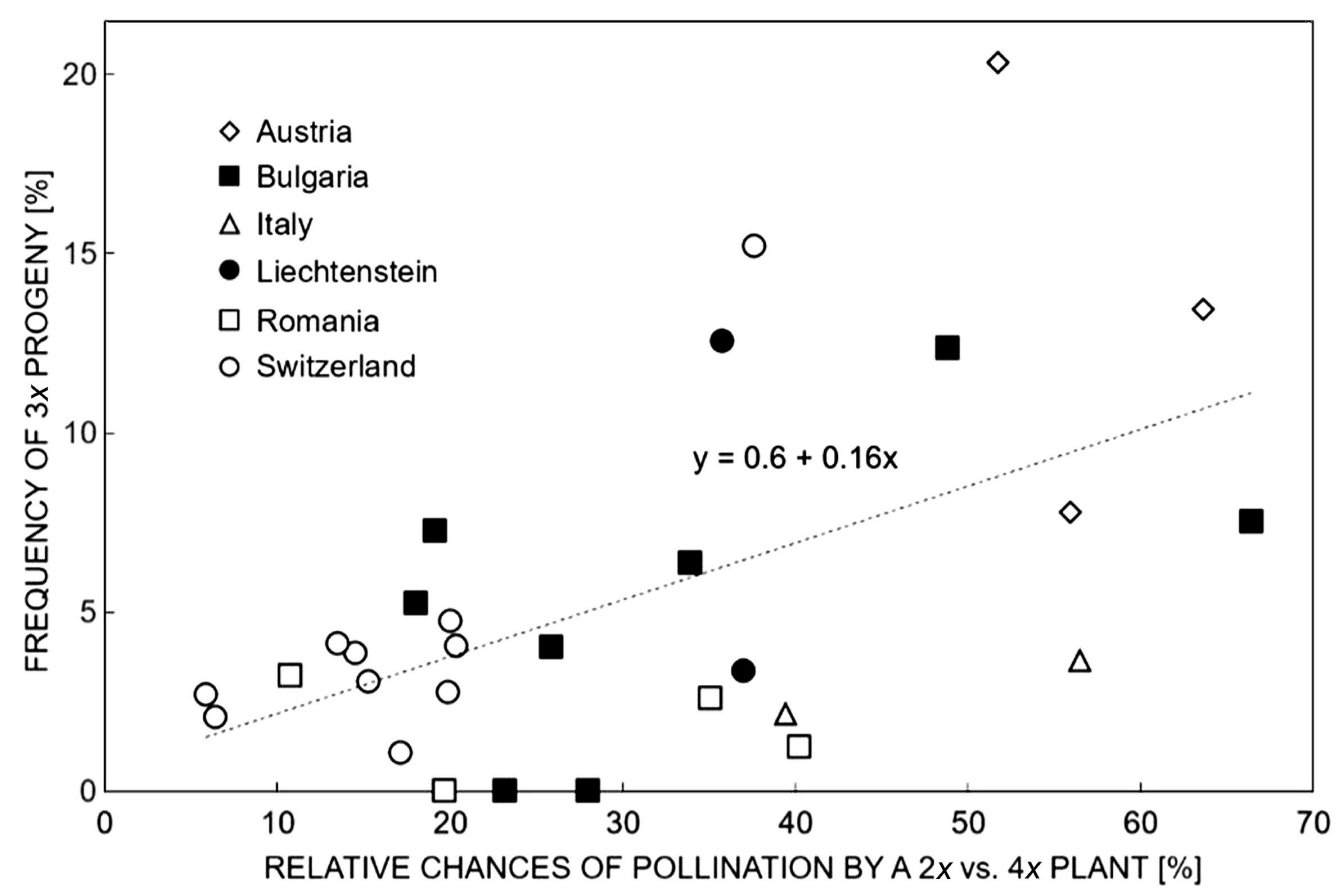

Fig. 2. The occurrence of triploid $(3 x)$ seedlings in progenies of 28 individual Festuca apennina $(4 x)$ plants originating from 6 European countries plotted against the relative chance of each F. apennina to be pollinated by a $2 x F$. pratensis plant and thus yielding $3 x$ progeny. Individual Festuca apennina plants were exposed to open pollination by a fixed number of randomly distributed $2 x F$. pratensis and $4 x$ F. apennina plants. Relative chances were calculated on the basis of distances to neighboring plants and flower synchrony with them. The regression coefficient $r^{2}=0.297$.

triploid hybrid $(14 F p+7 F g$-like) pollinated with a haploid pollen of $F p(7 F p)$. All three triploid progeny plants had the same chromosome constitution $(14 F p+7 F g$-like $)$ as their mother plant. Different scenarios are possible in this case, such as a haploid $7 F p$ egg cell after complete loss of the $F g$-like genome during meiosis, pollinated by a diploid pollen of $4 x$ Fape ( $7 F p$ and $7 F g$-like) or apomictic propagation from an unreduced egg cell of the triploid hybrid.

Pollen fertility, seed set, and seed germination from the isolation units, of natural hybrids of L. perenne $\times$
F. pratensis is shown in Table 4 Suppl. The pollen fertility was somewhat lower in the diploid hybrids with $3.9 \%$ (FpLp), compared to $7.8 \%$ in $L p L p F p$ triploid and $8.1 \%$ in $F p F p L p$ triploid. In diploid hybrids, seed set was $0.5 \%$ but the seed did not germinate, and no viable plants were produced. Seed set in the triploids $L p L p F p$ and $F p F p L p$ was 0.5 and $0.8 \%$ with the germination rate of $22.0 \%$ (13 plants produced) and $2.1 \%$ (14 plants produced), representing the fertility rate of 0.10 and $0.02 \%$, respectively.

The 13 progenies from maternal triploids $L p L p F p$ came from isolation units 2 and 3 , and 14 progenies 
Table 4. The genome composition and pollen fertility of the progeny of the triploid hybrids.

\begin{tabular}{lllll}
\hline Mother plant & Progeny & Isolation unit & Genome composition & Pollen fertility [\%] \\
\hline LpLpFp & 1 & 2 & $2 \mathrm{n}=28 ; 21 L p+7 F p$ & 62 \\
& 2 & 3 & $2 \mathrm{n}=21 ; 16 L p+5 F p$ & 2 \\
& 3 & 3 & $2 \mathrm{n}=20 ; 14 L p+6 F p$ & 36 \\
FpFpLp & 4 & 3 & $2 \mathrm{n}=21 ; 14 L p+7 F p$ & 4 \\
& 1 & 1 & $2 \mathrm{n}=21 ; 14 L p+7 F p$ & 27 \\
& 2 & 1 & $2 \mathrm{n}=21 ; 14 L p+7 F p$ & 29.7 \\
& 3 & 2 & $2 \mathrm{n}=21 ; 14 L p+7 F p$ & 30.7 \\
\hline
\end{tabular}

from maternal FpFpLp came from isolation units 1, 2, 3 , and 6 . The progenies produced from triploid hybrids (either with each other or with parental species) varied in genome composition (Table 4). Eight progeny plants were studied in detail. Seven of these plants retained the triploid chromosome constitution (including triploidy with one missing chromosome). The combination of parental gametes involved in the hybridization events could not be unambiguously determined, however, FpFpLp hybrids, hybridized with each other or with parental species (isolation units 2 and 1) produced progeny (four plants analyzed) with the genome constitution $L p L p F p$ (one plant with evidence of homoeologous recombination). This means, that one genome of $F$. pratensis was replaced by one genome of $L$. perenne. The reciprocal of this was not observed, $L$. perenne genome has never been replaced by the genome of $F$. pratensis; the progeny of $L p L p F p$ hybrids either possessed the same genomic composition as their mother plant (one plant), had substitutions of two $F p$ chromosomes by two $L p$ chromosomes (one plant) or showed elimination of one $F p$ chromosome. The only tetraploid progeny plant with genome constitution $21 \mathrm{Lp}+$ $7 F p$ chromosomes (thus, being $L p L p L p F p$ ) probably arose from the merge of unreduced gamete of the triploid and a normal gamete of diploid $L$. perenne.

The progeny of a $L p L p F p$ mother plant differed in pollen fertility. While tetraploid plant (No. 1) had pollen fertility at $62 \%$, only $2 \%$ pollen fertility was observed in the triploid plant (No. 2) with genome constitution $16 L p+5 F p$. Unexpectedly, aneuploid plant (No. 3) had high pollen fertility $(36 \%)$, much above that of all euploid triploids. On the contrary, all four triploid progeny plants from mother plant $F p F p L p$ had similar pollen fertility ranging from 17.7 to $30.7 \%$.

In natural hybrids, aerial tillering and vivipary were noted. These traits were also observed in a number of the progeny from these plants.

\section{Discussion}

Triploid hybrids between diploid F. pratensis and tetraploid $F$. apennina occurred frequently and with a clear altitudinal pattern in all six investigated grassland areas of the Swiss Alps. This confirms and expands the previous results
(Kopecký et al. 2018) where triploids were found much more frequently at about $1350 \mathrm{~m}$ a.s.1. than at 1550 and $1750 \mathrm{~m}$ a.s.l. The sympatric appearance of both parental species does not seem to be necessary for the widespread distribution of their triploid hybrids. Triploid hybrids were found at lower altitudes down to $996 \mathrm{~m}$ a.s.l. whereas no F. apennina was found in grassland below $1236 \mathrm{~m}$ a.s.1. (Fig. 1). Similarly, triploid hybrids occurred up to $1943 \mathrm{~m}$ a.s.l. while no F. pratensis was found above $1702 \mathrm{~m}$ a.s.l. Moreover, the maternity of the triploid hybrids sampled at different altitudes did not reflect the altitudinal distribution of their parental species. Even at the lowest altitudes (below $1225 \mathrm{~m}$ a.s.1.) where no $F$. apennina was found, most triploid hybrids were derived from a $F$. apennina mother (Table 2). Therefore, wind pollination of locally growing $F$. pratensis by more distant $F$. apennina plants growing at higher altitudes and subsequent shedding of hybrid seeds in the vicinity of the $F$. pratensis was not primarily responsible for the downward expansion of the triploid hybrids. Long-distance seed dispersal is likely to play a more important role for the spread of the triploid hybrids far beyond zones of co-occurrence of the two parent species than pollen dispersal by wind. Haymaking at high altitudes is not common in the grassland areas studied, thus human-mediated seed dispersal by fodder transport probably plays only a minor role. However, grazing cattle are often moved over long distances in the summer grazing systems prevailing at the regions of study. Near the end of the summer period when seeds are ripe on Fape, cattle are transferred from higher to lower altitudes to graze the regrowth, and are good candidates as vectors for the downward seed dispersal. "Bristly" grass seeds such as Nardus stricta or Festuca ovina, to which we may rightly also assign Festuca apennina seeds with their awns remain attached to coats of grazing animals when moving through grassland (Mouissie et al. 2005), more on sheep but also on cattle coats. Seeds are retained sufficiently long on sheep wool to be transported beyond $1 \mathrm{~km}$ distance but not as long on cattle coats. A more likely mode of long-distance dispersal of $F$. apennina seeds is endozoochory, a passage through the digestion system and deposition with faeces. Cosyns et al. (2005) studied the emergence of seedlings from cattle dung after the animals had grazed on extensively used grassland. Grasses of the genera Poa, Holcus, and Agrostis were among the 
most frequent species emerging. Festuca rubra seedlings also emerged, though at lower frequencies. Different Gramineae were also among the species that emerged from white-tailed deer pellets in the study of Myers et al. (2004). The frequent occurrence of both $4 x F$. apennina and $3 x$ hybrids in places were grazing cattle like to rest (so-called "Läger"), as observed in our previous study (Kopecký et al. 2018), supports the hypothesis that cattle faeces may be the main vector of the long-distance seed dispersal of $F$. apennina seed. Additionally, dung deposits boost the availability of nutrients and thus help to create an optimal environment for the establishment of the high nutrient demanding $F$. apennina and $3 x$ hybrids.

Triploid hybrids formed spontaneously in an experimental setting with open pollination among Fape and $F p$ (Fig. 2). In this field trial, we investigated the formation of hybrids in the progeny of Fape mothers only because most hybrids in nature are derived from Fape mothers. Moreover, hybrid progenies are much more easily detected when Fape is the seed parent due to the differential germination behavior of tetraploid and triploid seeds. While tetraploid Fape seeds require cold treatment for germination (Tyler et al. 1978), a seed that develops into a triploid hybrid has a much smaller requirement for cold treatment (Boller et al. 2018). This finding was confirmed in the study presented here. Almost all (97\%) of seedlings germinating without cold treatment were triploid hybrids, whereas a great majority of seedlings germinating after one or more cold treatment cycles were tetraploid $(86,92$, and $96 \%$ for one, two, or three cycles of the cold treatment, respectively). Analysis of the frequency of hybrid formation identified the metric distance and flowering synchrony to pollinating $F p$ or Fape plants growing nearby as a major source of variation. Assuming no self-pollination, the formation of triploid hybrids was only about six times less likely than would be expected from the vicinity to pollinating $F p$ vs. Fape plants. Thus, the compatibility of $F p$ pollen on a Fape stigma was at least $16 \%$ of the compatibility of Fape pollen. If a certain rate of self-pollination of Fape is assumed, the relative fertilization success of $F p$ pollen on Fape was even higher. The easy cross-fertilization of Fape pollinated with $F p$ contrasts with the cumbersome production of interspecific and intergeneric hybrids observed earlier in breeding programs; the seed parent is usually emasculated to avoid self-fertilization, but even then, the cross-fertilization rate is low. For example, Jenkin (1933) obtained only 12 F1 hybrids from 8000 manually emasculated florets of diploid $L$. perenne pollinated by diploid F. pratensis. Gröber et al. (1974) obtained less than $1 \%$ seed per emasculated florets of $F$. pratensis when pollinated with Lolium species. In their study, the combination $F$. pratensis $\times F$. arundinacea yielded the most viable seeds, $5.9 \%$ seeds per emasculated floret when diploid $F$. pratensis was the seed parent, and even $14.6 \%$ when $F$. arundinacea was the seed parent pollinated with autotetraploid $F$. pratensis. In our present study, some Fape plants produced much more hybrid progeny than expected from the vicinity to $F p$ pollinators. The highest rate of triploidy among progeny was $20.32 \%$ for a plant which had a $51.7 \%$ chance to be pollinated by $2 x F p$. Therefore, on this particular plant, fertilization success of pollen of $2 x F p$ was $(20.32 / 51.7) \times 100=40.01 \%$. Four more plants had the fertilization success above $32 \%$ (double of the average $16 \%$ ) of $F p$ pollen. This may suggest a genetic variation for the tendency to produce interspecific hybrids. Genetic systems controlling interspecific crossability are known in other plant species including $K r$ system in wheat (Krolow 1970). However, the heritability of this character has not been studied in this study.

Despite a relatively good chance of obtaining triploid hybrids in an experimental setting, hybrid seedlings were rare when the seed was collected on Fape plants in natural grassland (Table 2 Suppl.). The low number of hybrid seedlings contrasted with the high number of triploid hybrids occurring nearby. At the two localities where triploid seedlings were identified among the progeny of open-pollinated Fape, the abundance of triploid hybrids in nearby grassland was 49 and $21 \%$, but the abundance of triploid progeny from Fape was only 0.53 and $0.66 \%$. Thus, the abundance of triploid hybrids in the grassland was 32 to 92-times higher than the proportion of triploid progeny among seedlings. There are several possible explanations for this discrepancy.

1) Triploid hybrids may have a better chance of establishment under the specific conditions of these midaltitude sites due to their reduced cold requirement for germination. The cold requirement is a defense mechanism to avoid winter kill of young seedlings germinating in the autumn. However, direct germination after seed shedding may be more advantageous at lower altitudes with milder winters, as providing competitiveness to well-established seedlings in the spring. As climate change accelerates, triploid seed may be able to germinate and establish at higher altitudes and where there is a reduced cold period, and tetraploid seed may increasingly fail to germinate increasing the advantage of triploid seed.

2) Triploid hybrids exhibit extraordinary heterosis (hybrid vigor). Mid-parent heterosis of triploid hybrids over their Fp and Fape parents of up to $600 \%$ was observed by Boller et al. (submitted). All three triploid hybrids raised from open-pollinated Fape plants listed in Table 3 were markedly more vigorous than their corresponding tetraploid Fape half-sibs. A difference in vigor score of 2.5 units (8.94 vs. 6.45), as reported for the $1000 \mathrm{~m}$ a.s.l. site in the year after planting, H1, translated into a 3-fold higher dry mass yield according to the exponential regressions reported by Boller et al. (submitted). Thus, triploid hybrids are expected to be much more competitive in the pasture than tetraploid Fape. However, hexaploid seedlings (formed from the fusion of reduced and unreduced gametes of Fape) were significantly less vigorous than their tetraploid Fape half-sibs at high altitudes (Table 3), indicating their low competitiveness in the pastures. In these seedlings, no hybridization but polyploidization is involved, which did not show any benefits to plants studied here. Indeed, in the survey of the ploidy levels in six grassland areas reported here, none of the 1044 Festuca plants was hexaploid Fape.

3) The rates of triploid hybrids among seeds of open- 
pollinated Fape may have been much higher in the past when their parental species were more frequently cooccurring than today. This possibility is illustrated by pastures composed of triploid hybrids in the absence of both parental species (Table 1 and Fig. 1). Indeed, in the pasture "Loch" in the region Kamor with all 48 Festuca plants being triploid hybrids, these hybrids were also very competitive in the grassland biotopes. Over the 48 individual sampling points, we estimated that on average they contributed $32 \%$ (s.d. 21) to the yield of all grassland species present. Similarly, we did not find any other cytotype but triploids in several Swiss alpine pastures during our collection expedition in 2015 (Kopecký et al. 2016).

4) Many triploid hybrid seeds may have been brought to the pastures through long-distance seed dispersal from sites of more balanced co-occurrence of $F p$ and Fape, rather than having been formed and spread by seed shedding at the sites themselves.

Triploid hybrids were mostly sterile, but a small number of seeds were recovered from such plants exposed to pollen of $F p$ and Fape. However, their viability was low with just 0.29 of viable seeds per plant compared to Fape with 1572 of seeds per plant. They produced seedlings that were either triploid like their mother, or tetraploid. Unreduced eggs of a triploid Fape $\times F p$ mother were likely involved in the formation of tetraploid progeny. Triploid seedlings may have arisen via apomixis. Gröber et al. (1974) created interspecific and intergeneric hybrids of various species of Festuca, Lolium, and Bromus. They found that hybrids between parents of different ploidy were largely sterile, but particularly vigorous, and suggested that apomictic propagation of otherwise sterile hybrids might be a promising way to exploit their high yield potential in breeding. Apomictic propagation might contribute, in addition to rhizomatous expansion, to the large horizontal spread (up to $14.4 \mathrm{~m}$ ) of individual triploid hybrid genotypes observed by Kopecký et al. (2018). However, this contribution is probably small. The establishment of a triploid seedling originating from a new hybridization event between Fape and Fp seems more likely than the establishment of a triploid seedling from one of the very rare seeds of a triploid hybrid plant. In their natural habitats, open pollinated Fape plants form about $0.35 \%$ of hybrid seeds (Table 2 Suppl.), but in an experimental setting, triploid hybrid plants formed only $0.02 \%$ of viable seeds compared to Fape plants (Table 3 Suppl.). Thus, seed propagation of triploid hybrids may be a significant way of spreading only when none or very little $4 x$ Fape is present in the vicinity. Indeed, at the locality Ahorn, with $99 \%$ triploid hybrids among all Festuca sampled, Kopecký et al. (2018) found all 18 randomly sampled individuals of triploid hybrids to be genetically different, thus arisen from different hybridization events.

Diploid and triploid L. perenne $\times F$. pratensis hybrids, commonly known as Festulolium loliaceum, are found throughout the UK and Western Europe. This suggests that these hybrids can originate wherever the progenitor species grow sympatrically. These diploid and triploid hybrids differed: the diploids had a somewhat lower pollen fertility $(3.9 \%)$ and produced no viable plants from the 476 seeds which were allowed to germinate while triploids had higher pollen fertility $(7.8 \%$ in $L p L p F p$ and $8.1 \%$ in $F p F p L p$ ) with relatively high germination rates in triploid $L p L p F p$ hybrids $(\sim 22 \%)$ and lower, but still some germination in triploid $F p F p L p$ hybrids $(\sim 2 \%)$. The reason why triploids outperform diploids in the germination rate and, to a lesser extent, pollen fertility remains unknown. One may expect that homoploid $(L p F p)$ will show reduced (or completely absent) pairing of homoeologous chromosomes during meiosis leading to unbalanced and non-functional gametes. However, chromosomes of Festuca and Lolium display promiscuous pairing and recombination in Festulolium hybrids, including diploid homoploid of $L$. perenne $\times F$. pratensis (Kopecký et al. 2008; for visualization of meiosis in diploid $L$. perenne $\times$ F. pratensis hybrids, see https://olomouc.ueb.cas.cz/ getattachment/Research-groups/Kopecky-group/MeiosisWith-Labeled-Parental-Genomes.pdf.aspx?lang=en-US).

The fact that several germinating seeds of triploid mother plants were obtained from the isolation unit consisting exclusively of hybrids (unit 2), suggests that triploids represent the evolutionarily successful type. This is in line with the hypothesis of Husband (2004) that a 'triploid bridge' is expected to be a more frequent strategy for the establishment of hybrid genomes than via polyploidization of homoploid hybrids due to the low probability of fusion of two unreduced gametes in natural populations.

In some cases, pollen fertility increased considerably in the subsequent generation of these hybrids (up to $62 \%$.), which further increases the chances of their establishment in native grasslands. Besides increased pollen fertility, they also developed alternative strategies to persist in different environments: vivipary and aerial tillering. This mode of reproduction is not unexpected, as these hybrids frequently occur in water meadows subjected to seasonal flooding. The offspring of these hybrids, once backcrossed to L. perenne, retains the aerial tillering and vivipary, suggesting a genetic mechanism behind these traits, not triggered by the environment alone. These traits and increased fertility lead to increased competitiveness of $F l$. loliaceum. Gymer and Whittington (1976) and Kulik (2011) reported that $\mathrm{Fl}$. loliaceum can compete with other grass species in a sward under disturbed conditions. This agrees with the observations on other allopolyploids. In general, they display broader adaptation to novel environmental niches compared to their progenitor species, hence a greater ability to colonize disturbed and harsher habitats (Te Beest et al. 2012), leading to increased invasiveness (Pandit et al. 2011). The natural L. perenne $\times$ F. pratensis hybrids used in this experiment were collected from water meadows and their ability to survive waterlogging for at least a part of the year might be assumed to be an adaptive advantage. Similarly, Gymer and Whittington (1976) and Graiss (2011) studied the performance of Festulolium hybrids in plot experiments with $L$. perenne and $F$. pratensis under different experimental regimes and found that hybrids increased in proportion over time in most of the conditions. This may trigger potential utilization of natural 
Festulolium hybrids in breeding programs, as sources of novel gene combinations for areas prone to flooding.

The hybrid genomes were modified over generations. In two out of four progeny plants of $L p L p F p$, a reduction of $F$. pratensis chromosomes was seen. Similarly, in all four progeny plants of $F p F p L p$, one entire genome of $F p$ was replaced by that of $L p$, giving the genome composition of progeny $L p L p F p$. The predominance of Lolium genome over that of Festuca has been observed in other studies on the genome constitution of Festulolium hybrids. All commercial cultivars of $L$. multiflorum $\times F$. pratensis and $L$. perenne $\times F$. pratensis exhibit the prevalence of Lolium chromosomes over those of Festuca (Kopecký et al. 2006). Zwierzykowski et al. (2006, 2011) conducted a study over eight successive generations of such hybrids and observed a slow but consistent replacement of the Festuca by Lolium chromosomes.

In seven out of eight progeny plants, triploidy of the mother plants persisted. How these plants retain triploidy is an intriguing question. Some species of water frogs can reproduce via hybridogenesis. This means that during gametogenesis of triploids (ABB), they discard the genome of one of the parental species (A) and produce diploid gametes of the other parental species (BB). The hybrid triploidy $(\mathrm{ABB})$ is restored by fertilization of these gametes with haploid gametes from the parental species whose genome was eliminated (A). Thus, the population is always at the pseudo-F1 generation (Christiansen and Reyer 2009). However, this requires absence of homoeologous chromosome pairing and the chromosomes of Lolium and Festuca pair regularly. Alternatively, retention of triploidy might be triggered by apomixis. This appears as an unlikely general scenario, as only one out of six triploid progenies with 21 chromosomes had the same genome composition as the maternal plant. Thus, the retention of triploidy in our hybrids remains a mystery.

\section{Conclusions}

This paper demonstrates that even rare interspecific hybridization events may allow a new hybrid not only to survive but thrive and extend beyond the range of its progenitor species. As we move into an era of climate change with extremes of weather becoming the norm, new hybrids within the Lolium-Festuca complex may find new niches to colonize (Ghesquiere et al., 2010). In some cases, they might even outcompete and replace their progenitors: the triploid $F$. apennina $\times F$. pratensis hybrids reported here which do not require cold to germinate, and have superior vigour, are replacing the tetraploid parent $F$. apennina which needs a cold treatment to germinate. With milder winters at higher altitudes becoming the norm, tetraploid $F$. apennina may become less competitive with other species and even its hybrids, which germinate in the autumn and thus, have a head start over the parental species in the spring. As with natural hybrids between $L$. perenne and F. pratensis, which have found a niche in flooded areas where their parental species cannot compete, they offer possibilities of genetic combinations that can be utilized in breeding programs.

These hybrids can be the bridging species in transferring genes between the progenitor species. There is a certain degree of fertility in the hybrids allowing them to transfer their genetic material in hybridization events with their progenitor species creating unlimited new intra- and interspecific combinations. The frequent occurrence of easily detectable triploid hybrids lets us speculate that the formation of hybrids in nature may be far more common than generally believed.

A natural hybrid has several options to survive: 1) through apomixis or clonal reproduction via rhizomes in diploid or triploid hybrids; 2) through limited pollen fertility that allows mating with other hybrids or progenitor species; and 3) through unreduced gametes creating new allopolyploid combinations with increased fertility by restoration of diploid-like chromosome pairing behavior during meiosis.

We envisage that interspecific hybrids enabling the transfer of agriculturally beneficial genes and traits between species will play a crucial role in future breeding to mitigate the impacts of climate change.

\section{References}

Banfi, E., Galasso, G., Foggi, B., Kopecky, D., Ardenghi, N.M.G.: From Schedonorus and Micropyropsis to Lolium (Poaceae: Loliinae): new combinations and typifications. Taxon 66: 708-717, 2017.

Boller, B., Felder, T., Kopecky, D.: Tetraploid Festuca apennina is prone to produce triploid hybrid progeny when crossed with diploid Festuca pratensis. - In: Brazauskas, G., Statkevičiute, G., Jonavičiene, K. (ed.): Breeding Grasses and Protein Crops in the Era of Genomics. Pp. 33-38. Springer, Cham 2018.

Christiansen, D.G., Reyer, H.U.: From clonal to sexual hybrids: genetic recombination via triploids in all-hybrid populations of water frogs. - Evolution 63: 1754-1768, 2009.

Comai, L.: The advantages and disadvantages of being polyploid. - Nat. Rev. Genet. 6: 836-846, 2005.

Conert, J.C., Hegi, G.: Illustrierte Flora von Mitteleuropa. Band 1, Teil 3. Spermatophyta: Angiospermae: Monocotyledones 1 (2). Poaceae (Echte Gräser oder Süssgräser). [Illustrated flora of Central Europe. Volume 1, Part 3. Spermatophyta: Angiospermae: Monocotyledones 1 (2). Poaceae (grasses).] Parey Buchverlag, Berlin 1998. [In German]

Cosyns, E., Claerbout, S., Lamoot, I., Hoffmann, M.: Endozoochorous seed dispersal by cattle and horse in a spatially heterogeneous landscape. - Plant Ecol. 178: 149$162,2005$.

De Notaris, G.: Festuca apennina. In: Repertorium florae ligusticae 2116. P. 463. ex Regio Typographeo, Torino1844. [In Latin]

De Vere, N., Rich, T.C.G., Ford, C.R., Trinder, S.A., Long, C., Moore, C.W., Satterthwaite, D., Davies, H., Allainguillaume, J., Ronca, S., Tatrinova, T., Garbett, H., Walker, K., Wilkinson, M.J.: DNA barcoding the native flowering plants and conifers of Wales. - PLoS ONE 7: e37945, 2012.

Dolezel, J., Greilhuber, J., Lucretti, S., Meister, A., Lysak, M.A., Nardi, L., Obermayer, R.: Plant genome size estimation by flow cytometry: inter-laboratory comparison. - Ann. Bot. 82: 17-26, 1998.

Dolezel, J., Greilhuber, J., Suda, J.: Estimation of nuclear DNA 
content in plants using flow cytometry. - Nature Protocols 2: 2233-2244, 2007.

Ellstrand, N.C., Whitkus, R., Rieseberg, L.H.: Distribution of spontaneous plant hybrids. - Proc. nat. Acad. Sci. USA 93: 5090-5093, 1996.

Essad, S.: [Comparative cytogenetic and morphological research on origin of natural hybrids Festuca loliacea $2 \mathrm{n}$ and 3n.] Ann. Amelioration Plant. 16: 5, 1966. [In French]

Farragher, M.A.: On the occurrence of Festuca $\times$ Lolium hybrids in the Irish flora. - Irish nat. J. 18: 208-211, 1975.

Ghesquiere, M., Humphreys, M.W., Zwierzykowski, Z.: Festulolium. - In: Boller, B., Posselt, U.K., Veronesi, F. (ed.): Fodder Crops and Amenity Grasses. Handbook of Plant Breeding. Vol. 5. Pp. 293-316. Springer, New York Dordrecht - Heidelberg - London 2010.

Graiss, W., Krautzer, B., Pötsch, E.M.: Suitability of alternative grass species for grassland management in Austria under changing climatic conditions. - Grassland Sci. Eur. 16: 440442, 2011.

Grober, K., Matzk, F., Zacharias, M.: Studies on the development of the apomictic mode of reproduction in fodder grasses. I. Interspecific and intergeneric crosses. - Kulturpflanze 22: 159-180, 1974.

Gymer, P.T., Whittington, W.J.: Hybrids between Lolium perenne and Festuca pratensis. 2. Comparative morphology. - New Phytol. 72: 861-865, 1973.

Gymer, P.T., Whittington, W.J.: Factors influencing proportion of natural hybrids between Lolium perenne L. and Festuca pratensis Huds. in permanent pastures. - J. brit. Grassland Soc. 31: 165-169, 1976

Holub, J.: Reclassifications and new names in vascular plants 1. - Preslia 70: 97-122, 1998.

Humphreys, M.W., Thomas, H.M., Morgan, W.G., Meredith, M.R., Harper, J.A., Thomas, H., Zwierzykowski, Z., Ghesquiere, M.: Discriminating the ancestral progenitors of hexaploid Festuca arundinacea using genomic in situ hybridization. - Heredity 75: 171-174, 1995.

Humphreys, M.W., Harper, J.A.: Festulolium loliaceum, an understudied natural UK grass hybrid species that may procide benefits to UK grasslands withstanding the onsets of climate change. - Eur. Crop wild Relative Newslett. 6: 7-9, 2008.

Husband, B.C.: The role of triploid hybrids in the evolutionary dynamics of mixed-ploidy populations. - Biol. J. Linn. Soc. 82: 537-546, 2004.

Jauhar, P.P.: Cytogenetics of the Festuca-Lolium Complex. Relevance to Breeding. - Springer-Verlag, Berlin 1993.

Jenkin, T.J.: Interspecific and intergeneric hybrids in herbage grasses $=$ initial crosses. - J. Genet. 28: 205-264, 1933.

Kopecký, D., Felder, T., Schubiger, F.X., Mahelka, V., Bartos, J., Dolezel, J., Boller, B. Frequent occurrence of triploid hybrids Festuca pratensis $\times$ F . apennina in the Swiss Alps. - Alpine Bot. 128: 121-132, 2018.

Kopecký, D., Harper, J., Bertas, J., Gasior, D., Vrana, J., Hribova, E., Boller, B., Ardenghi, N.M.G., Simonikova, D., Dolezel, J., Humphreys, M.W.: An increasing need for productive and stress resilient Festulolium amphiploids: what can be learnt from the stable genomic composition of Festuca pratensis subsp. apennina (De Not.) Hegi? - Front. environ. Sci. 4: 66, 2016.

Kopecký, D., Loureiro, J., Zwierzykowski, Z., Ghesquiere, M., Dolezel, J.: Genome constitution and evolution in Lolium $\times$ Festuca hybrid cultivars (Festulolium). - Theor. appl. Genet. 113: 731-742, 2006.

Kopecký, D., Lukaszewski, A.J., Dolezel, J.: Meiotic behaviour of individual chromosomes of Festuca pratensis in tetraploid
Lolium multiflorum. - Chromosome Res. 16: 987-998, 2008.

Krolow, K.D.: [Studies on the cross-compatibility between wheat and rye]. - Z. Pflanzensuchtg. 64: 44-72, 1970. [In German]

Kulik, M.: Persistency of Festulolium loliaceum strains in comparison with other species depending on the method of utilization. - Grassland Sci. Eur. 16: 106-108, 2011.

Lewis, E.J.: Lolium L. - In: Stace C.A. (ed.): Hybridization and the flora of the British Isles. Pp. 555-557. Academic Press, London 1975.

Lohaus, R., Van de Peer, Y.: Of dups and dinos: evolution at the K/Pg boundary. - Curr. Opin. Plant Biol. 30: 62-69, 2016.

Madlung, A.: Polyploidy and its effect on evolutionary success: old questions revisited with new tools. - Heredity 110: 99104, 2013.

Masoudi-Nejad, A., Nasuda, S., McIntosh, R.A., Endo, T.R.: Transfer of rye chromosome segments to wheat by a gametocidal system. - Chromosome Res. 10: 349-357, 2002.

Matsuoka, Y.: Evolution of polyploid triticum wheats under cultivation: the role of domestication, natural hybridization and allopolyploid speciation in their diversification. - Plant Cell Physiol. 52: 750-764, 2011.

Mouissie, A.M., Vos, P., Verhagen, H.M.C., Bakker, J.P.: Endozoochory by free-ranging, large herbivores: ecological correlates and perspectives for restoration. - Basic appl. Ecol. 6: 547-558, 2005.

Myers, J.A., Vellend, M., Gardescu, S., Marks, P.L.: Seed dispersal by white-tailed deer: implications for long-distance dispersal, invasion, and migration of plants in eastern North America. - Oecologia 139: 35-44, 2004.

Pandit, M.K., Pocock, M.J.O., Kunin, W.E.: Ploidy influences rarity and invasiveness in plants. - J. Ecol. 99: 1108-1115, 2011.

Peto, F.H.: The cytology of certain intergeneric hybrids between Festuca and Lolium. - J. Genet. 28: 113-119, 1933.

Rieseberg, L.: Hybrid origin of plant species. - Annu. Rev. Ecol. Evol. System. 28: 359-389, 1997.

Schreiber, J.: Staining plant and animal chromosomes by the feulgen-acetocarmine sequence. - Stain Technol. 29: 285-291, 1954.

Soltis, D.E., Soltis, P.S.: Molecular data and the dynamic nature of polyploidy. - Crit. Rev. Plant Sci. 12: 243-273, 1993.

Stace, C.A.: Hybridization and the Flora of the British Isles. Academic Press, London 1975.

Te Beest, M., Le Roux, J.J., Richardson, D.M., Brysting, A.K., Suda, J., Kubesova, M., Pysek, P.: The more the better? The role of polyploidy in facilitating plant invasions. - Ann. Bot. 109: 19-45, 2012.

Tyler, B., Borrill, M., Chorlton, K.: Studies in Festuca. 10 Observations on germination and seedling cold tolerance in diploid Festuca pratensis and tetraploid F. pratensis var. apennina in relation to their altitudinal distribution. - J. appl. Ecol. 15: 219-226, 1978.

Wendel, J.F.: The wondrous cycles of polyploidy in plants. Amer. J. Bot. 102: 1753-1756, 2015.

Wit, F.: Natural and experimental hybrids of ryegrasses and meadow fescue. - Euphytica 13: 294-304, 1964.

Zwierzykowski, Z., Kosmala, A., Zwierzykowska, E., Jones, N., Joks, W., Bocianowski, J.: Genome balance in six successive generations of the allotetraploid Festuca pratensis $\times$ Lolium perenne. - Theor. appl. Genet. 113: 539-547, 2006.

Zwierzykowski, Z., Zwierzykowska, E., Taciak, M., Kosmala, A., Jones, R.N., Zwierzykowski, W., Ksiazczyk, T., Krajewski, P.: Genomic structure and fertility in advanced breeding populations derived from an allotetraploid Festuca pratensis $\times$ Lolium perenne cross. - Plant Breed. 130: 476-480, 2011. 